\section{Rotas críticas de mulheres em situação de violência: depoimentos de mulheres e operadores em Porto Alegre, Rio Grande do Sul, Brasil}

\author{
Critical trajectories of female victims of gender \\ violence: discourse analysis of women and staff \\ professionals in Porto Alegre, Rio Grande \\ do Sul State, Brazil
}

Stela Nazareth Meneghel 1

Fernanda Bairros 2

Betânia Mueller 3

Débora Monteiro 4

Lidiane Pellenz de Oliveira ${ }^{3}$

Marceli Emer Collaziol 3

\title{
Introdução
}

1 Escola de Enfermagem, Universidade Federal do Rio Grande do Sul, Porto Alegre, Brasil.

2 Faculdade de Medicina, Universidade Federal do Rio Grande do Sul, Porto Alegre, Brasil.

3 Universidade do Vale do Rio dos Sinos, São Leopoldo, Brasil.

${ }^{4}$ Universidade Estadual do Rio Grande do Sul, Porto Alegre, Brasil.

Correspondência

S. N. Meneghel

Escola de Enfermagem,

Universidade Federal do Rio Grande do Sul.

Rua São Manoel 930, Porto Alegre, RS 90620-110, Brasil. smeneghel@hotmail.com

\section{Abstract}

This qualitative study aims to describe the trajectories of female victims of gender violence in Porto Alegre, Rio Grande do Sul State, Brazil. The methodology included in-depth interviews with women and staff, attempting to map the critical paths of women when they made the decision to seek professional help. We interviewed 21 women victims of gender violence and 25 professionals, including law enforcement officials, health and social workers, and nongovernmental organizations. The women's trajectories in the services were mapped, identifying facilitating factors and obstacles in the process of breaking with gender violence. The victims reported: pressure by professional staff to return to their marriages and police inefficiency in providing protection. The discourse of law enforcement officials and health and social workers showed a range of different concepts regarding violence, medicalization of violence, and network fragmentation.

Violence Against Women; Domestic Violence; Critical Route
Em 1990, a violência contra a mulher foi reconhecida como um problema de saúde pública pela Organização Mundial da Saúde (OMS), que considera tal ação um obstáculo para o desenvolvimento socioeconômico e uma violação dos direitos humanos 1 .

A perspectiva de gênero para compreender a violência contra a mulher resultou de um longo processo de discussão, em que foi fundamental a participação do movimento feminista. Trabalhar com a categoria gênero significa assumir que a violência decorre de relações hierárquicas de poder entre homens e mulheres na sociedade e não se deve a doenças, problemas mentais, álcool/ drogas ou características inatas às pessoas 2 .

Para estudar as violências perpetradas contra as mulheres sob o prisma de gênero, utilizamos o conceito de patriarcado adotado pelas feministas contemporâneas, entendendo-o como um sistema sociopolítico que impregna e comanda o conjunto das atividades humanas, coletivas e individuais, incluindo a diferenciação de papéis e as hierarquias entre os sexos ${ }^{3}$. Embora adotemos a perspectiva do feminismo marxista, que tem como central o conceito de patriarcado 4,5 , não ignoramos a contribuição dos estudos culturais e o feminismo das diferenças.

Ao incorporar a violência como um tema de pesquisa acadêmico houve a preocupação em 
dimensionar o problema na sociedade. Atualmente, dados de pesquisa indicam uma elevada magnitude da violência perpetrada contra as mulheres em cifras que oscilam entre $15 \%$ a $70 \%$ em diferentes países 1,6.

No Brasil, a institucionalização das demandas sociais para atenção à violência contra as mulheres propiciou a criação das delegacias da mulher e das casas abrigo nos anos 1980; mais recentemente, a Lei $n^{\circ}$. 11.340/2006, chamada Lei Maria da Penha, inovou ao criar os juizados especiais para tratar essa questão 7 . A lei conceitua a violência doméstica como qualquer ação ou omissão baseada no gênero que cause morte, lesão, sofrimento físico, sexual ou psicológico e dano moral ou patrimonial, no âmbito da unidade doméstica ou em qualquer relação íntima de afeto, tendo por base as relações de gênero ${ }^{8}$.

Dentre as iniciativas realizadas para compreender o fenômeno violência de gênero, destacamos a proposta desenvolvida pela Organização Pan-Americana da Saúde (OPAS), denominada rota crítica, que investigou o trajeto percorrido pelas mulheres para romper com a violência em dez países latino-americanos 9. Pioneiro, o estudo, realizado na década de 1980, não incluiu o Brasil, fato que motivou esta pesquisa, baseada nos referenciais e métodos desenvolvidos na experiência anterior, adaptando-os à realidade brasileira.

A investigação sobre a rota crítica na América Latina e Caribe constatou que existem poucos recursos sociais, de saúde e comunitários efetivos para ajudar as mulheres a romper com a situação de violência ${ }^{9}$. No Brasil, o trajeto das mulheres nos serviços que compõem a chamada rede de enfrentamento às violências tem sido pouco avaliado, embora, no momento atual, vários grupos de pesquisa investiguem essas rotas 10,11,12,13,14. Em um estudo realizado na Região Metropolitana de Porto Alegre, Rio Grande do Sul, observou-se uma situação similar à dos países latino-americanos, ou seja, a trajetória das mulheres que decidem romper com a violência é longa, marcada por avanços e retrocessos, desprovida de apoio e, em muitas situações, ocorre revitimização, causada pelos serviços que deveriam cuidar delas 15 .

Portanto, esse é um problema atual que diz respeito não apenas aos investigadores, mas aos operadores sociais, tornando de extrema pertinência tanto a avaliação do trajeto das mulheres pelos serviços que prestam atendimento, quanto a reflexão crítica acerca dessas vivências. O objetivo principal desta pesquisa foi estabelecer a trajetória de mulheres em situação de violência de gênero, identificando os pontos críticos, propondo medidas de intervenção e fomentando a construção de redes de combate às violências na cidade de Porto Alegre.

\section{Trajeto metodológico}

Este é um estudo de abordagem qualitativa, que procurou estudar a violência contra a mulher na sua dimensão singular, por meio dos significados dados pelos sujeitos a fatos do seu contexto sociocultural. Este tipo de pesquisa permite melhor compreensão de fenômenos complexos e únicos, das dimensões subjetivas e simbólicas, assim como dos comportamentos, contextos e processos vividos pelos atores sociais 16,17 . O delineamento metodológico foi adaptado da investigação desenvolvida pela OPAS, A Rota Crítica de Mulheres Afetadas pela Violência Intrafamiliar na América Latina ${ }^{9}$, e este artigo constitui um recorte da pesquisa maior denominada Rotas Críticas: O Caminho das Mulheres no Enfrentamento das Violências, ocorrida no período de 2008 a 2010.

A investigação foi realizada na cidade de Porto Alegre. Foram entrevistadas mulheres em situação de violência e operadores de instituições que atuam na problemática da violência de gênero.

As informações foram obtidas por meio de entrevistas em profundidade adaptadas do protocolo inicial da investigação realizada na América Latina 18 . Os roteiros usados com as mulheres tinham por objetivo identificar o trajeto realizado por elas quando decidem buscar ajuda, a percepção da efetividade do atendimento recebido, assim como aspectos que facilitaram ou dificultaram o processo de rompimento com as violências. Os roteiros usados com os operadores procuravam identificar como se dava o atendimento às mulheres e incluíram tipos de encaminhamento, uso de protocolos e sistemas de referência.

As mulheres entrevistadas haviam realizado contato com serviços que compõem a rede de atenção, sendo a maioria indicada pelos operadores. Foram entrevistadas 21 mulheres em situação de violência, com idades entre 17 e 55 anos, pertencentes aos setores médios e de baixa renda. A maioria tinha o Ensino Fundamental, eram solteiras, embora vivessem com companheiro, e quase todas tinham filhos. No momento da entrevista, sete trabalhavam; as demais estavam em casa. Elas denunciaram a ocorrência das violências física (4), psicológica (3), física e psicológica (9), patrimonial (4) e sexual (1). As entrevistas foram feitas nas dependências da Delegacia da Mulher (6), do Juizado de Violência Doméstica e Familiar (6), da Casa de Passagem (3), do Centro de Referência a Víti- 
mas de Violência (3), da Escola Especial (2) e do Conselho Tutelar (1).

Os operadores sociais foram selecionados por sua representatividade nos serviços e interesse em participar. $\mathrm{O}$ contato se fez por meio telefônico, momento em que as pesquisadoras se apresentavam e convidavam para uma entrevista. Os operadores que constituíram a amostra intencional atuavam no setor saúde - uma unidade básica de saúde (UBS) e três hospitais de referência; na educação - duas escolas municipais, uma delas para jovens albergados; no setor policial - Delegacia da Mulher e Departamento Médico Legal; no setor jurídico - Ministério Público, Defensoria Pública e Juizado Especial da Violência Familiar e Doméstica; na ação social e direitos humanos - Centro de Referência a Vítimas de Violência e casa de passagem, e três ONGs. Exerciam as funções de juíza, professora, médico, enfermeiro, escrivão, promotora, defensor público, delegada, operadores e/ou profissionais de serviços de ação social, jurídicos e de saúde, além de militantes de organizações não governamentais. Ao todo, eram 25 operadores que lidam com a temática da violência, sendo 21 mulheres e 4 homens.

Os depoimentos dos operadores do setor educacional não foram usados pelo fato de a Secretaria de Educação do Município de Porto Alegre não possuir programas dirigidos à violência contra a mulher. Os das ONGs também não o foram porque estas não prestam atendimento direto às usuárias.

As entrevistas foram gravadas, transcritas, e o número total foi determinado pelo efeito de saturação das informações prestadas. O texto resultante dos depoimentos dos operadores e das mulheres foi utilizado para a construção de um corpus e, após a leitura exaustiva do material, foram identificados e categorizados os depoimentos das mulheres e dos operadores referentes à trajetória percorrida pelas mulheres. Esses excertos foram categorizados como "rotas críticas", sendo subdivididos de acordo com o setor de atendimento: jurídico, policial, ação social, saúde, educação e ONGs. Optou-se por usar conjuntamente os depoimentos dos operadores e das mulheres, que mostram perspectivas complementares ou divergentes em face de um mesmo fato. Foram selecionados excertos sobre os atendimentos prestados nos serviços e na rede, os fatores facilitadores e inibidores que influenciam as rotas e as diferentes concepções de violência. Nessa etapa da análise, utilizou-se o programa NVivo (QSR International - Americas - Inc., Cambridge, Estados Unidos).

Durante o processo de análise temática 16,19, fizemos uso de algumas ferramentas da análise crítica do discurso ${ }^{20}$. Atentamos não apenas para os conteúdos das conversas, mas também para o processo dialógico das entrevistas, que inclui o uso da retórica para modular um fato, as contradições na linha argumentativa de um mesmo falante e outros mecanismos usados na conversação, como as justificativas, o refazer a opinião quando questionado, o salientar determinadas palavras, a atitude de apoiar um fato e/ou pessoa e, em seguida, contrapor-se estes.

Esta pesquisa foi aprovada pelo Comitê de Ética em Pesquisa da Universidade do Vale do Rio dos Sinos; os participantes concordaram em participar no estudo, leram e assinaram um Termo de Consentimento Livre e Esclarecido. Todas as mulheres entrevistadas já haviam iniciado a rota crítica, isto é, haviam dado a conhecer a situação de violência, não incluindo situações em que os operadores soubessem da existência da violência, sem que a mulher houvesse tornado público.

\section{A rota crítica das mulheres em Porto Alegre}

A apresentação e discussão das informações sobre a rota crítica percorrida pelas mulheres em Porto Alegre refere-se, principalmente, aos setores policial, jurídico e de saúde.

A rede de enfrentamento à violência contra a mulher na cidade de Porto Alegre organiza-se de modo tal, que uma mulher em situação de violência geralmente se dirige a uma delegacia de polícia ou da mulher. Neste local, é lavrado o Boletim de Ocorrência, o qual fica à espera da realização de inquérito durante seis meses. Quando existe lesão corporal, a vítima é encaminhada ao Departamento Médico Legal e, se houver pedido de medida protetiva, abre-se um processo, que é enviado diretamente ao Juizado da Violência Doméstica, onde a medida é deferida em 48 horas. Caso haja necessidade de um defensor, a mulher é encaminhada ao Ministério Público.

Além da Delegacia da Mulher, o primeiro contato pode ocorrer em um serviço de saúde, assistência social, centro de referência ou conselhos de direitos, principalmente o Conselho Tutelar e os Centros de Referência da Assistência Social. Há, na cidade, dois Centros de Referência para Vítimas de Violência e uma Casa Abrigo para albergar mulheres e filhos, cuja entrada ocorre por encaminhamento da rede básica.

Em relação ao setor saúde, o Programa de Assistência às Mulheres Vítimas de Violência Sexual disponibiliza atendimento em todas as UBS, em três hospitais de referência e em três Unidades de 
Pronto Atendimento da Secretaria Municipal de Saúde de Porto Alegre.

Nesta cidade, estão ainda situadas as Coordenadorias Estadual e Municipal da Mulher e diversas ONGs que prestam assessoria e informações.

\section{Iniciando o processo}

A rota das mulheres em situação de violência inicia com a decisão de romper o silêncio e denunciar. Ao mapear a rota percorrida pelas mulheres de Porto Alegre, percebemos que a maior parte das entrevistadas, antes de procurar um serviço, precisa dar-se conta de que está sofrendo violência. Essa situação nem sempre é identificada, já que muitas foram socializadas para aceitar como naturais o uso da violência na resolução dos conflitos entre gêneros nas relações conjugais 2,21.

Normalmente, as mulheres relatam a violência vivida a pessoas próximas, familiares, amigos ou colegas de trabalho, porém nem sempre encontram empatia e solidariedade, principalmente quando as concepções de gênero e família são muito tradicionais. As famílias mostram uma atitude contraditória, entre apoiar a mulher e aconselhar a permanência na relação, reforçando a posição feminina de subordinação e minimizando os conflitos entre os cônjuges, permanecendo aqueles na esfera do privado 12 .

Ainda assim, mesmo com limitações, familiares e amigos oferecem um espaço de proteção e podem ser, junto com outros serviços comunitários, o principal suporte para resistir às violências.

\section{O setor policial}

Embora muitas vivam situações de violência de longa data, a rota das mulheres inicia oficialmente quando o fato se torna público, geralmente mediante registro de uma ocorrência em uma delegacia. No Brasil, há, atualmente, mais de 300 Delegacias da Mulher; no entanto, Porto Alegre, um município com mais de um milhão de habitantes, conta com apenas uma. As operadoras das delegacias da mulher, embora se deem conta dos limites nas ações que podem disponibilizar, têm um discurso politizado acerca dos direitos da mulher e do papel das delegacias 22,23,24:

"O papel da delegacia seria registrar a ocorrência, intimar o agressor pra ser ouvido, buscar provas da lesão corporal e era isso. Só que nós estamos fazendo, além disso, um trabalho social que está nos sobrecarregando (...) O papel da delegacia seria única e exclusivamente criminal, mas não é o que vem acontecendo, ainda mais depois da Lei
Maria da Penha: a gente tem os acompanhamentos em casa para retirar os pertences, levar a um albergue ou familiar. Isso a gente faz, está previsto na lei e é positivo. Infelizmente, por ser o órgão que fica sempre aberto, com funcionários plantonistas para atender, tudo entra pela delegacia" (Operadora policial, Delegacia da Mulher).

Historicamente, o setor policial tem sido considerado negligente quanto à proteção de mulheres agredidas 25. No Brasil, as Delegacias da Mulher são bastante conhecidas e procuradas 26, mas também são os serviços que sofrem maior quantidade de críticas. Todas as mulheres que entrevistamos conheciam a Delegacia da Mulher ou tinham estado em uma, deixando transparecer que possuem noção de direitos:

Pesquisadora: "Quando a senhora sofreu essa violência, quais atitudes tomou?".

Entrevistada: "Eu fui na delegacia da mulher, registrei, fiz corpo [de] delito, fui no Pronto Socorro, fiz tudo que tinha que fazer, tudo por dentro da lei" (Mulher em situação de violência).

Mesmo assim, algumas acreditavam que a realização do Boletim de Ocorrência na Delegacia da Mulher significa a resolução de todo o problema.

"Eu fazia a ocorrência todinha ali [na Delegacia da Mulher] e achava que dali me chamariam" (Mulher em situação de violência).

Um dos aspectos criticados em relação às Delegacias da Mulher refere-se à escuta focada na queixa. Assim como os profissionais de saúde, que, ao ouvir a história clínica das usuárias, não se interessam por detalhes adicionais das narrativas, as policiais, ao buscar dados para a organização do inquérito, centram a escuta na queixa, dirigindo a conversa, interrompendo quando querem outras informações e desconsiderando detalhes que lhes parecem supérfluos 27,28. Essa é uma das dificuldades de comunicação ou um ponto crítico na rota, o que já tem sido estudado por vários pesquisadores e que também foi observado neste trabalho:

"Tu chega lá não tem ninguém, não tem um suporte, elas simplesmente fazem o boletim e te mandam embora e acabou o assunto, não é tomada uma providência na hora, pra proteger a mulher no caso da mulher não ter pra onde ir..." (Mulher em situação de violência).

A Lei Maria da Penha instituiu a aplicação de medidas protetivas de urgência que incluem o afastamento do agressor do domicílio e a proibição de este se aproximar da mulher, a fim de preservar a integridade física e psicológica da ofendida ${ }^{8}$. Algumas entrevistadas expressaram descrédito na lei em virtude do descumprimento das medidas protetivas por parte dos agressores: 
"Qualquer coisa que acontecesse era para chamar a polícia e mostrar a medida protetiva, mas até a polícia chegar deu né, já tá feito o dano (...) Agora tu chama ligeiro e eles dizem que não têm viatura, diz que não podem entrar dentro de casa, certo? Aí o cara quebra a cara da gente e a gente tem que ficar quieta" (Mulher em situação de violência).

A Lei Maria da Penha não tem sido aceita por todos os setores da sociedade, principalmente os mais conservadores, incluindo-se uma parcela de operadores do direito. $\mathrm{O}$ discurso descrito a seguir é do operador do judiciário e manifesta uma crítica ao dispositivo legal, ressaltando a periculosidade da medida protetiva, uma vez que estimula o agressor a fazer uso da violência e da força física. Ele não questionou os entraves na aplicação da lei ou as deficiências no sistema policial na efetiva proteção das mulheres, mas colocou a responsabilidade na vítima, acusando-a de não avaliar criteriosamente o pedido de proteção:

"A medida de afastamento contra o agressor é uma medida extremamente severa na vida dos dois, porque tem consequências tanto para a pessoa que vai ficar em casa, como para a pessoa que vai sair. Depois que a polícia vai embora, ele mete o pé na porta e arrebenta ou mata ela, e a mulher fica desprotegida, ela não vai ficar com um policial na porta, então a protetiva é uma medida perigosa também. A gente não tem como saber o que vai acontecer, todo mundo pede medida de afastamento, já tá na boca do povo. Às vezes, a violência que elas se referem é a do casamento desgastado e daí a solução desse casal não é aqui, simplesmente retirar uma pessoa de casa" (Operador, Ministério Público).

Os operadores da Delegacia da Mulher entrevistados salientaram o aumento no número de ocorrências após a instauração da Lei Maria da Penha, embora tenham afirmado que a maioria dos inquéritos tem sido arquivada e poucos agressores foram sentenciados:

"Na verdade, quase 90\% das ocorrências que saem daqui e vão para audiência judicial, as mulheres acabam se retratando, desistindo e isso posterior a Lei Maria da Penha, não mudou quase nada. Até o começo do ano, nenhum agressor havia sido condenado na vara da violência doméstica, que já tem um ano, ninguém foi condenado. Ou seja, chegaram lá e fizeram um acordo, ou a mulher desistiu" (Operador policial/Delegacia da Mulher).

Por outro lado, ouvimos depoimentos sobre o amparo prestado pela ação policial impactando na cessação da violência:

Pesquisadora: "Que resultados obteve em sua busca de ajuda? Conseguiu deter a violência?”.
Entrevistada: "Sim, depois que ele soube que eu tinha vindo na Delegacia da Mulher não me agrediu mais" (Mulher em situação de violência física).

\section{O setor jurídico}

Após a denúncia efetuada na Delegacia da $\mathrm{Mu}-$ lher, é aberto um processo e enviado ao Ministério Público, onde é designado um defensor para acompanhar as mulheres que não têm recursos. Os defensores nem sempre se inteiram do processo ou conhecem a pessoa que irão representar antes da audiência. Em adição, existe muita rotatividade entre eles, de modo que, durante o processo, uma mulher pode ser atendida por vários profissionais. Diante desse procedimento, as mulheres não se sentem devidamente ouvidas, entendidas e amparadas:

"Falei pro advogado, e o advogado nada fez, só que a justiça gratuita é muito suja e eles não fazem nada pra gente. A gente tem que comer o pão que o diabo amassou, porque a gente não sabe ler e é pobre, a mulher pobre e negra não tem direito de falar, eles não deixam a gente falar" (Mulher em situação de violência).

Os processos são agendados para audiência pública no único Juizado da Violência Doméstica e Familiar da cidade de Porto Alegre. As audiências são realizadas com periodicidade semanal e duram, em média, dez minutos. Nessa situação, as mulheres são inquiridas para decidir se querem manter a denúncia, reconciliar ou separar:

"No Foro, a juíza disse que tinha que fazer acordo com ele, voltar para casa, porque no momento eu não tinha onde ficar, e a juíza disse que as coisas iam melhorar. Ela insistiu que eu tinha que voltar, que hoje em dia os casais têm que voltar. Dois meses, ele me botou pra rua de novo $e$ quando eu fui procurar a justiça disseram que já tava arquivado" (Mulher em situação de violência patrimonial).

Na audiência, elas são levadas a tomar decisões rapidamente, havendo uma pressão para que reconsiderem a queixa e retornem ao domicílio. Os operadores do judiciário, ao estimular a permanência da mulher no domicílio conjugal, evitando adotar medidas do âmbito criminal, perpetram uma revitimização às mulheres $\mathrm{e}$ deixam espaço para a manutenção das violências 23,29:

Pesquisadora: "Ele continua agredindo a senhora?".

Entrevistada: "Continua agredindo, na parada do ônibus, em qualquer lugar, me chama de tudo que é coisa e diz: 'Vai te queixar na justiça, tu mesma viu que a juíza fez com que tu voltasse 
pra dentro de casa! Eu faço de ti o que eu quiser. Se eu te matar agora, eu vou dizer que tu que entrou dentro de casa. Tive que ficar quieta, minha filha, e aguentar tudo para não dormir na rua" (Mulher em situação de violência).

Na mediação efetuada no Juizado da Violência Doméstica, os agressores são enviados a ONGs, como Amor Exigente, Alcoólicos Anônimos e outras, que oferecem atendimento para doenças como alcoolismo, droga, depressão, ou agressão. Dessa maneira, fica patente a concepção da violência de gênero como uma doença decorrente de distúrbios mentais ou comportamentos de risco 2,30 . Tal concepção implica a necessidade de serviços médicos e de atenção psicossocial para tratar as pessoas afetadas; portanto, muitas das audiências terminam com a prescrição de que homens, mulheres ou ambos frequentem um serviço de atenção à saúde:

"O imenso trabalho feito no juizado é a seleção, a triagem dos casos e encaminhamentos, então esses que precisam de tratamento são encaminhados, dentro do possível, porque eu não estou conseguindo o apoio da saúde. Os grupos de auto-ajuda têm colaborado, os AA, os Narcóticos Anônimos e o Amor Exigente. A gente tem notado que a melhor intervenção para a violência é encaminhar para tratamento (...). A grande maioria dos processos termina nesta primeira audiência" (Operador jurídico, Juizado da Violência Doméstica).

O encaminhamento aos serviços psicossociais ou de saúde sem assegurar a proteção à mulher propicia a manutenção de situações de violência e o descrédito, tanto na lei, quanto nos serviços jurídicos e policiais 25,29 . Este ponto crítico decorre de tratar-se a violência apenas em suas manifestações individuais, retirando-se a conotação social do problema.

\section{O setor saúde}

Do setor saúde seria esperado o papel de articulador da rede de enfrentamento à violência, porém os serviços de saúde ainda não constituem uma porta de entrada efetiva para os casos em questão 30,31.

Os operadores desses serviços formulam um discurso ambivalente em relação às intervenções sobre a violência de gênero. Eles conhecem a política de enfrentamento à violência contra a mulher, mas consideram que os serviços não estão funcionando adequadamente e não se sentem capacitados para atender os casos:

"A mulher vai ser encaminhada para os locais de atendimento; se ela está com risco de ter fratura, nós fazemos o encaminhamento para o HPS
[Hospital de Pronto-Socorro]. A gente orienta a procurar a promotoria pública para as questões de afastamento do agressor. Nós não temos acompanhamento, mas encaminhamos para a rede. A gente sabe que é difícil; acompanhamento da mulher adulta não é fácil" (Operador saúde, UBS).

Um dos entrevistados questiona a própria condição de hospital de referência pelo modo como se está ofertando o serviço:

"Não adianta dizer que é um centro de referência e tu não ser referência coisa nenhuma, porque referência tem que dar atendimento, tem que ser uma estrutura pra atender o todo, e não assim. Eu atendo de segunda à sexta-feira, até às cinco horas da tarde, e como é que eu sou referência e atendo só nesses horários?" (Operador saúde, hospital).

Há operadores que usam retórica defensiva, responsabilizando e culpando a vítima, além de transferirem a responsabilidade ao outro 32.

Pesquisador: "Como registram as situações de violência contra a mulher?”.

Entrevistado: "A vigilância diagnostica, e nós somos notificados depois. Eles gostariam que as unidades acompanhassem esses casos, mas não fazemos por falta de estrutura" (Operador saúde, UBS).

Neste diálogo, o trabalhador de saúde referese à dificuldade de diagnóstico das violências no território, já que essas situações são conhecidas pela UBS através do Serviço de Vigilância, o qual comunica ao local os casos que poderiam ter sido identificados nesse nível de atuação. Verifica-se, portanto, que permanece a invisibilidade de mulheres agredidas em unidades de atenção básica 33,34 .

Pesquisador: "Vocês fazem algum tipo de acompanhamento, como ir até as casas?".

Entrevistado: "Se for realmente necessário, a gente vai, mas nós temos ido principalmente para idosos e crianças, não tanto para mulheres vítimas de agressão. Até porque a gente já teve relatos de casos que o pessoal foi muito mal recebido pela família. O pessoal foi agredido, aí depois disso ninguém mais foi (...). O marido veio no posto $e$ fez um escândalo, queria bater em todo mundo, veio com arma e tudo." (Operador saúde, UBS).

O tom preponderante da resposta é o de justificativa, atribuindo aos autores das agressões a responsabilidade pela não realização de ações de acompanhamento. Os profissionais da saúde mostram-se atemorizados em relação ao atendimento de violências e, apesar de toda a discussão sobre esse tema, ainda o consideram um assunto do âmbito privado.

Embora o setor saúde continue privilegiando as intervenções pautadas no modelo biomédico e a maioria das práticas se restrinja ao tratamento das lesões, ouvimos narrativas indicativas de 
que, mesmo de modo pouco sistematizado, há profissionais de saúde que diagnosticam a violência contra as mulheres e realizam medidas de intervenção eficazes e oportunas, mostrando sensibilidade, empatia e adequação:

"Foi a médica do posto que viu meu pescoço, porque eu escondia, tinha vergonha de todo mundo. Ela disse: 'Tu fica bem calma hoje, ajeita tuas coisinhas, não fala nada pro teu marido e amanhã tu vem aqui nesse horário'. Ela me tratou super bem e, então, eu fui para o Departamento Médico Legal, para a assistente social e aqui na Casa Viva Maria" (Mulher em situação de violência física).

Observamos, não somente na fala dos profissionais da saúde, mas também na daqueles de outros setores, que muitas vezes eles se limitam a ouvir a queixa da mulher e a encaminhá-la a outros locais. Acreditamos que a escuta pode significar uma ação qualificada quando uma mulher precisa narrar a sua história e tornar pública uma violência 35,36; todavia, pode ser apenas um paliativo quando o serviço não está apto a fornecer a atenção que seria de sua competência, fazendo com que a usuária repita sua história apenas para mandá-la a outro lugar, sem responsabilizar-se pelo atendimento. $\mathrm{O}$ fato de ter que dirigir-se a inúmeros locais, contar e recontar as suas histórias, ter a veracidade das informações questionadas, sofrer procedimentos em duplicidade ou desnecessários, é outro ponto crítico da rota das mulheres, uma situação debatida e criticada pelos movimentos sociais de mulheres há um longo tempo.

\section{A rota percorrida pelas mulheres de Porto Alegre}

No estudo da OPAS sobre a rota crítica 9 , foi identificada uma série de fatores facilitadores e inibidores da decisão de romper com as violências. Os facilitadores compreendem atitudes pessoais, que vão desde o cansaço por anos de humilhações ou a indignação pelo abuso de um filho, até a percepção do incremento na violência e do risco iminente de vida. Dentre as situações que dificultam o rompimento, estão o medo, a culpa, a vergonha, as pressões familiares, as limitações materiais e a ineficácia institucional, compreendendo as atitudes negativas dos operadores, a burocracia, a falta de orientação, a revitimização.

Na pesquisa realizada em Porto Alegre, as mulheres citaram como fatores facilitadores a própria existência da Lei Maria da Penha, o atendimento satisfatório de alguns operadores e a rapidez de alguns procedimentos.
Como limitadores, elas criticaram a dificuldade de compreender as orientações e processos, a fragmentação dos serviços que compõem a rede e a ausência de um centro onde pudessem receber atenção integral. Outros pontos críticos foram a pressão dos operadores jurídicos para que as agredidas permaneçam na relação conjugal e a incapacidade da polícia em assegurar às demandantes a proteção de medidas protetivas. Já foi observado que há situações em que os serviços de apoio jurídico-legais, por meio da pressão, podem retirar o poder das mulheres que atendem para que estas adotem determinados comportamentos ou refaçam suas histórias para moldar-se a um protocolo ou documento legal 24,29 .

Somem-se aos fatores inibidores percebidos pelas mulheres outros identificados na fala dos operadores, incluindo a concepção da violência como doença que direciona o foco para o tratamento, isentando o agressor de responsabilidade pelos seus atos e expondo as mulheres a violências adicionais. Ademais, sabe-se que muitas das que fracassaram nas primeiras tentativas, levarão muito tempo até se fortalecerem para reiniciar a rota 9 .

No campo da saúde, as equipes que entrevistamos não se sentem capazes de prestar atenção integral às mulheres em situação de violência conjugal, limitando-se a tratar as lesões físicas e a referi-las ao setor policial. Apesar da existência de um Sistema de Notificação para as Violências, não existem protocolos específicos que avaliem o risco iminente e não se disponibilizam sistematicamente atividades de cunho individual ou coletivo 37 que possam promover o fortalecimento emocional destas mulheres.

Um descompasso que sentimos entre a rota das mulheres e a rota ofertada pelos serviços é a divergência nos tempos dos interlocutores. Há situações que demandam uma ação rápida e eficaz dos serviços, como o deferimento e a aplicação de uma medida protetiva, o que pode assegurar a sobrevivência de uma mulher ameaçada de morte. Em outros momentos, é preciso dar um tempo maior à mulher para que ela se fortaleça antes de continuar o caminho, sem pressionála para resolver sua vida em apenas uma audiência. Perceber a violência como uma violação ética dos direitos humanos das mulheres 38 pode ajudar os operadores a atuar nas iniquidades sociais de gênero, as quais constituem a raiz do problema, e não apenas procurar minimizar as suas consequências e efeitos em nível individual e comportamental.

Assim como outros investigadores 12,14 , percebemos que não é possível identificar um fluxo preciso, um itinerário único ou mais eficiente; ao 
contrário, o caminho é diverso para cada história relatada. A maioria das mulheres entrevistadas iniciou a rota fazendo uma ocorrência na Delegacia da Mulher; algumas estavam sendo ouvidas no juizado; outras estavam em vias de desistir ou haviam retornado ao domicílio conjugal; outras ainda estavam dando seguimento ao processo. Enfim, a resistência das mulheres na longa rota que precisam percorrer depende da intersecção entre as iniquidades sociais produzidas pelos sistemas classista, patriarcal e racista e a singularidade/subjetividade de cada uma ${ }^{25}$. Ou, como elas mesmas disseram:

\section{Resumo}

Esta pesquisa de abordagem qualitativa tem por objetivo estabelecer a trajetória de mulheres em situação de violência de gênero na cidade de Porto Alegre, Rio Grande do Sul, Brasil. A metodologia incluiu entrevistas em profundidade com mulheres e operadores sociais, procurando mapear a rota crítica das mulheres quando decidem procurar ajuda. Foram entrevistadas 21 mulheres em situação de violência e 25 operadores das áreas jurídica, policial, ação social, saúde e organizações não governamentais. A rota percorrida pelas mulheres nos serviços foi mapeada e analisada, sendo identificados aspectos facilitadores e limitadores no processo de romper com a violência. As mulheres relataram a pressão dos operadores para que retornem ao casamento e a ineficiência do setor policial para darlhes proteção. Nos depoimentos dos operadores, perceberam-se as diferentes concepções de violência entre os serviços, a medicalização da violência e a fragmentação da rede.

Violência Contra a Mulher; Violência Doméstica; Rota Crítica
"Para te falar a verdade, acho que eu não tive muito apoio, eu contei comigo mesma, com a minha coragem, com a minha vontade de decidir fazer as coisas sozinha e era isso" (Mulher em situação de violência).

Ao término desta pesquisa sobre a rota crítica das mulheres na cidade de Porto Alegre, entendemos que acompanhar o trajeto delas pelos serviços pode contribuir para um melhor entendimento sobre os pontos críticos que dificultam o seu itinerário e a efetivação das políticas públicas empenhadas na superação das violências.

\section{Colaboradores}

S. N. Meneghel coordenou a pesquisa e participou da concepção e elaboração do artigo. F. Bairros, B. Mueller, D. Monteiro, L. P. Oliveira e M. E. Collaziol contribuíram na concepção e elaboração do artigo.

\section{Agradecimentos}

Ao Conselho Nacional de Desenvolvimento Científico e Tecnológico (CNPq; Edital Universal 2007, processo: 472238/2007-8). 


\section{Referências}

1. Krug E, Dahlberg L, Mercy J, Zwi AB, Lozano R. Informe mundial sobre la violencia y la salud. Washington DC: Organización Panamericana de la Salud/Organización Mundial de la Salud; 2003.

2. Biglia B, San Martin C. Estado de wonderbra. Entretejiendo narraciones feministas sobre las violencias de género. Barcelona: Virus Editorial; 2007.

3. Delphy C. Patriarcado (teorias do). In: Hirata H, Laborie F, Le Doaré H, Senotier D, organizadoras. Dicionário crítico do feminismo. São Paulo: Editora Unesp; 2009. p. 173-8.

4. Saffioti H, Almeida S. Brasil: violência, poder, impunidade. In: Camacho T, organizador. Ensaios sobre violência. Vitória: EDUFES; 2003. p. 85-114.

5. Saffiotti H. Gênero e patriarcado. In: Castillo-Martin M, Oliveira S, organizadores. Marcadas a ferro. Brasília: Secretaria Especial de Políticas para as Mulheres; 2005. p. 35-76.

6. Ellsberg M, Jansen HA, Heise L, Watts CH, GarciaMoreno C; WHO Multi-country Study on Women's Health and Domestic Violence against Women Study Team. Intimate partner violence and women's physical and mental health in the WHO multicountry study on women's health and domestic violence: an observational study. Lancet 2008; 371:1165-72.

7. Santos CM. Da Delegacia da Mulher à Lei Maria da Penha: lutas feministas e políticas públicas sobre violência contra mulheres no Brasil. Coimbra: Centro de Estudos Sociais, Universidade de Coimbra; 2008. (Oficina, 301).

8. Brasil. Lei no ${ }^{\circ}$. 11.340, de 7 de agosto de 2006. http:// www.planalto.gov.br/ccivil_03/_Ato2004-2006/ 2006/Lei/L11340.htm (acessado em 01/Dez/2010).

9. Sagot M. Ruta critica de las mujeres afectadas por la violencia intrafamiliar en América Latina: estudios de caso de diez paises. San José: Organización Panamericana de la Salud; 2000.

10. Schraiber L, d'Oliveira AF, Hanada H, Figueiredo W, Couto M, Kiss L, et al. Violência vivida: a dor que não tem nome. Interface Comun Saúde Educ 2003; 7:41-53.

11. Schraiber L, d'Oliveira AF. Violência dói e não é direito. São Paulo: Editora Unesp; 2005.

12. Silva MCMV. Rotas críticas: os (des)caminhos trilhados por mulheres em situação de violência doméstica na busca de ajuda [Dissertação de Mestrado]. São Paulo: Faculdade de Medicina, Universidade de São Paulo; 2008.

13. Dantas-Berger SM, Giffin K. A violência nas relações de conjugalidade: invisibilidade e banalização da violência sexual? Cad Saúde Pública 2005; 21:417-25.

14. Mota JC. Violência contra a mulher praticada pelo parceiro íntimo: estudo em um serviço de atenção especializado [Dissertação de Mestrado]. Rio de Janeiro: Escola Nacional de Saúde Pública, Fundação Oswaldo Cruz; 2004.

15. Presser AD, Meneghel SN, Hennington EA. Mulheres enfrentando as violências: a voz dos operadores sociais. Saúde Soc 2008; 17:126-37.
16. Minayo MC. O desafio do conhecimento: pesquisa qualitativa em saúde. São Paulo: Editora Hucitec/ Rio de Janeiro: ABRASCO; 1992.

17. Bauer MW, Gaskell G. Pesquisa qualitativa com imagem, texto e som. Petrópolis: Editora Vozes; 2002.

18. Shrader E, Sagot M. La ruta critica que siguen las mujeres afectadas por la violencia intrafamiliar. Protocolo de investigación. Washington DC: Organización Panamericana de la Salud; 1998.

19. Bardin L. Análise de conteúdo. Lisboa: Edições 70; 1977.

20. Iñiguez L. Manual de análise do discurso em Ciências Sociais. Petrópolis: Editora Vozes; 2004.

21. Meneghel SN, Sagot M. Práticas discursivas, gênero e sofrimento emocional. In: Meneghel SN, organizadora. Rotas críticas II: ferramentas para trabalhar com gênero. Santa Cruz do Sul: EDUNISC; 2009. p. 52-63.

22. Gregori MF. Delegacias de Defesa da Mulher de São Paulo: paradoxos e paralelismos. In: Debert GG, Gregori MF, Piscitelli A, organizadores. Gênero e distribuição da justiça: as Delegacias de Defesa da Mulher e a construção das diferenças. Campinas: Núcleo de Estudos de Gênero Pagu, Universidade Estadual de Campinas; 2006. p. 57-87.

23. Debert GG, Oliveira MB. Os modelos conciliatórios de solução de conflitos e a "violência doméstica". Cadernos Pagu 2007; (29):305-37.

24. Pasinato W, Santos CM. Mapeamento das Delegacias da Mulher no Brasil. Campinas: Núcleo de Estudos de Gênero Pagu, Universidade Estadual de Campinas; 2008.

25. Moe AM. Silent voices and structured survival: battered women's help seeking. Violence Against Women 2007; 13:676-99.

26. Schraiber LB, d'Oliveira AFPL, Couto MT, Hanada H, Kiss LB, Durand JG. Violência contra mulheres entre usuárias de serviços públicos de saúde da Grande São Paulo. Rev Saúde Pública 2007; 41:35967.

27. Kiss LB, Schraiber LB, d'Oliveira AFP. Possibilidades de uma rede intersetorial de atendimento a mulheres em situação de violência. Interface Comun Saúde Educ 2007; 11:485-501.

28. Ostermann AC. Análise da conversa (aplicada) como uma abordagem para o estudo de linguagem e gênero: o caso dos atendimentos a mulheres em situação de violência no Brasil. In: Meneghel SN, organizador. Rotas críticas II: ferramentas para trabalhar com gênero. Santa Cruz do Sul: EDUNISC; 2009. p. 142-71.

29. McDermott MJ, Garofalo J. When advocacy for domestic violence victims backfires: types and sources of victim disempowerment. Violence Against Women 2004; 10:1245-66.

30. Schraiber LB, d'Oliveira AFPL, Portella AP, Menicucci E. Violência de gênero no campo da saúde coletiva: conquistas e desafios. Ciênc Saúde Coletiva 2009; 14:1019-27. 
31. Granja E, Medrado B. Homens, violência de gênero e atenção integral em saúde. Psicol Soc 2009; 21:25-34.

32. Soares LE. A eficácia pragmática da sensibilidade antropológica e a inversão do modelo defensivo. Observações sobre o lugar do simbólico na política pública de segurança. In: Corrêa M, organizador. Gênero e cidadania. Campinas: Núcleo de Estudos de Gênero Pagu, Universidade Estadual de Campinas; 2002. p. 21-30.

33. Hyman I, Garuge S, Stewart D, Ahmad F. Primary prevention of violence against women. Womens Health Issues 2000; 10:288-93.

34. d'Oliveira AF, Schraiber LB. Atenção integral à saúde de mulheres em situação de violência de gênero: uma alternativa para a atenção primária em saúde. Ciênc Saúde Coletiva 2009; 14:1037-50.
35. Boltanski L. El amor y la justicia como competências. Tres ensayos de sociologia de la acción. Buenos Aires: Amorrurtu Eds.; 2000.

36. Oliveira MLP, Meneghel SN, Bernardes JS. Modos de subjetivação de mulheres negras: efeitos da discriminação racial. Psicol Soc 2009; 21:266-74.

37. Meneghel SN, Barbiani R, Steffen H, Wunder AP, Roza MD, Rotermund J, et al. Impacto de grupos de mulheres em situação de vulnerabilidade de gênero. Cad Saúde Pública 2003; 19:955-63.

38. Libal K, Parech S. Reframing violence against women as a human rights violation: Evan Stark's Coercive Control. Violence Against Women 2009; 15:1477-89.

Recebido em 19/Mar/2010

Versão final reapresentada em 29/Dez/2010 Aprovado em 01/Fev/2011 